\title{
Juventudes locales, entre la crisis y la acción colectiva ${ }^{2}$
}

\author{
Local Youth, between \\ the Crisis and the Collective Action
}

\section{Resumen}

El presente ensayo de reflexión busca abordar la crisis de sentido — y la crisis material— que afrontan las sociedades contemporáneas, a partir de las voces de diferentes autores de las Ciencias Sociales que han aportado algunos elementos de orden conceptual para pensar dichas crisis; terminando con una aproximación sobre cómo la acción colectiva podría ser un terreno para hacerle contrapeso a sus determinantes. Esta reflexión se construye a partir del desarrollo de la investigación "Organizaciones populares y subjetividades juveniles: el caso de la localidad de Kennedy", llevada a cabo por el Observatorio de Procesos de Organización Comunitaria (OPOC) de la Corporación Universitaria Minuto de Dios, la cual saldrá publicada en el año 2013.

Palabras clave: juventud, Crisis, Sociología, Trabajo Social, liderazgo, acción colectiva, organizaciones sociales.

\section{Abstract}

This reflective paper attempts to tackle the crisis of meaning -and material crisis- that faced contemporary societies. As a starting point to understand these crises will be considered a variety of voices from different social studies researchers who have contributed with some conceptual framework. Finally, the paper outlines how the collective action would be a field to counteract the determinant of these crises. This reflection is based on a research study entitled "Popular Organizations and Youth Subjectivities: the Case of Kennedy" conducted by the Observatory of Processes of Communitarian Organization (OPOC- in Spanish)" at Corporación Universitaria Minuto de Dios that will be published in the year 2013.

Keywords: Youth, Crisis, Sociology, Social Work, Leadership, Collective Action, Social Organizations.

Recibido el 11 de marzo de 2013 y aprobado el 31 marzo de 2013

1 Sociólogo de la Universidad Nacional de Colombia. Magíster en investigación social interdisciplinaria de la Universidad Distrital Francisco José de Caldas. Coordinador del Observatorio de Procesos de Organización Comunitaria (OPOC) de la Corporación Universitaria Minuto de Dios. Correo electrónico: sociologiaumd@gmail.com

2 Artículo de reflexión derivado de la investigación Organizaciones populares y subjetividades juveniles, el caso de la localidad de Kennedy del Observatorio de Procesos de Organización Comunitaria (OPOC), Uniminuto, 2012. 


\section{El sentido significa \\ la significación y la finalidad; solo tiene sentido aquello que va a alguna parte;}

lo que no va alguna parte es insensato"

Mafesolli, 2008

-Ey Martín ¿contra qué

teme la gente revelarse abora?

Ya nada tiene sentido de todos modos.

-Son los tiempos, mira a tu alrededor,

la persona más buscada en Internet

es la jodida Paris Hilton.

Película Die Welle. Dennis Gansel.

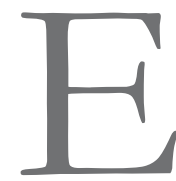

1 presente articulo de reflexión está motivado por los siguientes interrogantes generales, los cuales fueron tomando forma a lo largo de un pro-

ceso de revisión documental, en torno a los temas relacionados con la categoría de juventud. Los cuestionamientos son: ¿Vivimos una crisis? $¿$ ¿Se trata de una crisis económica o de orden cultural? ¿Cómo se relaciona la crisis y la acción colectiva en un contexto como el nuestro?

Cuando empezamos a leer sobre juventud, rápidamente aparecieron referencias a la crisis. Al paso salían expresiones como el fin de las finalidades (Auge, 2008), el desanclaje simbólico (Perea, 2008), la saturación como síntoma del cambio (Sorokin, 1960), los malestares de la Modernidad (Taylor, 1994), la personalización (Lipovetsky, 2003), el desordenamiento cultural (Martín Barbero, 2009), entre otros conceptos que proponen la inmanencia de una situación crítica para las sociedades contemporáneas, y en particular, para los jóvenes, quienes parecen ser sus personajes principales. Desde diferentes aparatos teóricos y disciplinares, aludiendo a distintas imágenes y metáforas, los autores parecen coincidir en la existencia de un momento convulso.
Además, como el interés central de la investigación que desarrollábamos por ese entonces — titulada Organizaciones populares y subjetividades juveniles: el caso de la localidad de Kennedy — eran las acciones colectivas y las organizaciones sociales, encontrarnos con la crisis nos puso a pensar acerca de si la contravía a este momento crítico podría estar en las colectividades, grupos y procesos mancomunados, que en el mundo de lo juvenil tienen un lugar profuso, pero también desorganizado y efímero.

El resultado de ese asombro se consigna en este ensayo. En él hablaremos de esa crisis, sentida por autores de distintas latitudes, y pensaremos su relación con los procesos identitarios y de consumo cultural, para terminar con una reflexión sobre la acción colectiva como escenario de subjetivación y de elaboración de sentidos y proyectos colectivos.

\section{Apuntes sobre la crisis}

En el libro La ética de la autenticidad Charles Taylor denuncia algo que parece ser un sentir generalizado entre los sujetos contemporáneos: "La gente ya no tiene la sensación de contar con un fin más elevado, con algo por lo que vale la pena morir $[\ldots]$ La gente perdía esa visión más amplia porque prefería centrase en su vida individual" (1994, p. 39).

El filósofo advierte que en las sociedades actuales hay tres síntomas de una profunda crisis:

El primer temor estriba en lo que podríamos llamar perdida de sentido, la disolución de los horizontes morales. La segunda concierne al eclipse de los fines, frente a una razón instrumental desenfrenada. Y la tercera refiere a la perdida de libertad (Taylor, 1994, p. 45).

En síntesis, para Taylor, el sujeto contemporáneo experimenta una pérdida de dirección y significado, aparejada de un sobre-dimensionamiento del cálculo de intereses. Una constante acción racional con arreglo a fines, pero sin una finalidad ulterior, por ponerlo en términos de Max Weber, sería nuestra paradoja. Dirigimos el más mínimo 
movimiento vital de nuestra cotidianidad hacia el logro de un interés, a veces propio, a veces ajeno, pero carecemos de finalidades últimas.

De la misma manera que la aparente libertad representa una encrucijada a la vez fácil y a la vez insoportable de cargar, la contradicción señalada por Perea en su libro Qué nos une:

Es la paradoja del símbolo que conmueve a la sociedad actual: la Multiplicidad sin límites de los signos, coexiste con el más profundo vacío de sentido. Nunca antes los símbolos tuvieron tal grado de disponibilidad, circulantes por miles en la incesante parafernalia de los medios de comunicación; no obstante, nunca como ahora se vivió una carencia tan pronunciada de proyección y horizonte compartido (2008, p.32).

En un momento plagado de imágenes, en donde el ojo humano ha tenido que trabajar como nunca, no es muy clara la imagen de un futuro posible, la cual se dibuja y se desdibuja con las manecillas del reloj. La pérdida de sentido alude al debilitamiento de las finalidades. La vida se experimenta como desprovista de un destino ulterior. "La deriva se vende como libertad. Que cada cual decida lo que mejor le convenga" (Perea, 2008, p. 31). La escuela, la fábrica, la iglesia, la familia, las relaciones comunales, la nación, entre otras, parecen no tener ya un sentido sagrado, si no uno muy lábil que debe ser entendido de manera siempre nueva en el contexto en que pretenda ser conocido.

Se nos obliga a cambiar de trabajo frecuentemente; cambiamos de amor, de religión e incluso de proyecto de vida con la facilidad del sujeto que aprendió a morir y renacer muchas veces en la misma piel. La velocidad de este "mundo hostil" (Bauman, 2003) produce nauseas a quienes vamos de pasajeros en la inmensa esfera girante.

Esta visión pragmática debe matizarse con los sentidos que los sujetos construimos en el terreno de lo próximo, en el mundo de la vida, para usar la expresión fenomenológica. Sin embargo, a un nivel general, pareciera que los elementos que daban solidez a la vida de los individuos se han ido haciendo gaseosos y que esos sentidos mu- chas veces terminan siendo obsolescentes muy pronto u obedecen, sin saberlo, más a prácticas de reproducción cultural que a intentos contrahegemónicos. Y dentro de ello, esas fuentes de sentido colectivo se secan y los sujetos tienen que volver a buscar nuevos yacimientos, quizás menos caudalosos. Al respecto, Carlos Mario Perea plantea:

Los antiguos abrevaderos de identidad se deshacen: la cohesión en torno a la nación es disputada por numerosas fuentes de lealtad, la clase social no designa una segmentación transversal traducida en actores colectivos, la democracia y el partido político ven minada su capacidad de representación. En medio del naufragio la única certeza que se impone es el poder inconmovible del capital, ese que perdió la ligazón con el destino de la sociedad, enceguecido como anda con las consignas de la inversión y el crecimiento (2008, p. 24).

En el mundo del desordenamiento cultural (Martín Barbero, 2009), en el mundo líquido (Bauman, 2003), en el mundo de la flexibilidad laboral, de la comunicación desterritorializada, vemos a la crisis tomar múltiples formas, mientras buscamos el sentido en oasis de símbolos. Mientras tanto, los poderes, fuertemente reíficados, se fortalecen, ya no desde la coacción directa sino desde la seducción:

[...] el futuro del capitalismo parece más seguro que nunca. El control social se convierte en una tarea más fácil. Los costosos métodos panópticos de control, cargados de disenso como están, pueden desecharse o reemplazarse por un método menos costoso y más eficiente de seducción (Bauman, 2006, p. 153).

Tal parece que la crisis es tan visible que puede reconocerse desde distintos puertos. Además, su consecuencia lógica, el fortalecimiento del capital, la desazón, el ensanchamiento de las asimetrías, deben seguir siendo motivo de reflexión de las Ciencias Sociales, y en particular, del Trabajo Social, el cual ha asumido como misión la transformación de la realidad. Esta crisis debe comprenderse en sus dimensiones simbólicas y culturales (como crisis de sentido, como el debilitamiento de horizontes morales, como la experiencia de agotamiento de los sujetos) y en sus dimensiones 
materiales (como mantenimiento de los poderes económicos tradicionales, como la flexibilización del trabajo, como sofisticación del capitalismo y de sus asimetrías). Al respecto, Perea señala:

El enganche de tiempo completo asumido como carrera a lo largo de la vida -la conquista de un siglo de luchas laborales- es sustituido por el trabajador temporal, integrado por tiempos limitados según lo dictamine la conveniencia del proyecto en marcha [...] La movilidad se impone en la esfera de la producción erosionando el vinculo del trabajo y, por esa vía, deshaciendo la pertenencia clasista (2008, p. 35).

Un éxito atroz del sistema capitalista contemporáneo: disminuir estructuralmente las posibilidades de vinculación entre obreros, estudiantes, campesinos, etc. La referencia constante a la individualidad como el territorio de todas "las recompensas", como el escenario de lo significativo, como herramienta única de supervivencia, deviene en los obstáculos para el establecimiento de los vínculos sociales. Con esto no queremos decir que la gente no se articule en torno a proyectos colectivos; simplemente subrayamos cómo esta articulación parece ser el resultado de la búsqueda de una recompensa individual, la más de las veces. Más allá de las precisiones que debe hacerse sobre la comunidad como concepto, el pensar comunitario, la posibilidad de ser con, desde y a través del otro, tiene una implicación en la construcción de sujetos políticos y en la factibilidad de proyectos que hagan contrapeso a la hegemonía homogenizante y desvinculante de las sociedades contemporáneas.

Hasta aquí hemos abordado la crisis en términos abstractos, como un proceso que nos involucra a todos, más allá de las condiciones específicas de clase, ciclo vital, etc. Sin embargo, nuestra intención es pensar la crisis en relación con las juventudes locales, como sujetos históricos determinados.

A pesar de la aparente tribalidad, unión y falsa comunidad que nos propone el consumo cultural y sus implicaciones sociales, las fronteras, tal como las entiende Marc Auge (2012) en su texto La comunidad ilusoria, tienden a reproducir como elemento articulador la búsqueda de una utopía autista y simplemente hedonista, aunque se muestren como reivindicación de una lucha política por la equidad y la igualdad, dos conceptos tan taquilleros y a veces vacíos en algunos procesos de movilización y organización juvenil. Volveremos sobre esto más adelante.

Tanto desde lo cultural, como desde el mundo de lo material, la crisis tiene como epicentro la ruptura que el individuo experimenta con el orden de lo colectivo, esa exagerada personalización (Lipovetsky, 2003), ese extrañar lo comunitario (Bauman, 2003), ese desanclaje simbólico y material, representan claramente lo crítico del telón de fondo en el que experimentamos la vida. De nuevo Perea nos permite sustentar esta afirmación:

El desasimiento que experimenta el ciudadano en relación con el trabajo y el Estado nacional halla su encuadre en una matriz única de sentido: el mercado autorregulado despedaza la conexión con un orden colectivo objetivo, un orden que arde más allá del fuero interno individual pero al que, no obstante, cada ser humano se remite. En el pasado dicho orden permaneció como clave de edificación de los dispositivos colectivos (2008, p. 23).

Este es un croquis a blanco y negro de la crisis: la paradoja entre la multiplicidad y velocidad con la que circulan los símbolos y la ausencia del sentido, aparejada de unas condiciones laborales y de una relación con el trabajo en donde se eliminan las posibilidades de articulación a los sujetos con los órdenes colectivos. Los interrogantes que nos surgen, en consecuencia lógica con lo aquí planteado, son: ¿Qué papel juega la acción colectiva y las organizaciones sociales hoy, en esta crisis? Y ¿cómo aparece la crisis y la acción colectiva en el mundo de los jóvenes en nuestro contexto?

\section{Los jóvenes y la crisis}

En el apartado anterior citamos a Perea con la paradoja entre la multiplicidad de símbolos y el vacío de sentido de las sociedades contempo- 
ráneas. Pongamos en diálogo esa idea con lo que plantea Martín Barbero frente a las sociedades contemporáneas:

En una sociedad que padece el déficit simbólico quizás más grande de la historia y que lo tapona saturándose de signos, lo joven atraviesa nuestros imaginarios y pesadillas cobrando sentido de símbolo (2009, p. 32).

Las pautas publicitarias (protagonistas de un proceso de construcción social del sentido del mundo de los objetos), el cine, la televisión y la música, parecen cada vez más enraizadas en lo juvenil, y para ser más específicos, en lo adolescente.

La música de mayor circulación (casi siempre asociada a la pista de baile como lugar paradigmático del disfrute y del encuentro con el otro) anuló cualquier tipo de reflexión adulta al interior de las canciones de alta circulación masiva. En los años setenta, en Hispanoamérica, además de todo el hedonismo que siempre ha permeado y permeará la música, era usual encontrar cantautores como Serrat, Piero o Spinetta, hablando de diferentes temas asociados a la experiencia vital, cultural y política de los sujetos. En los noventa, una canción como Mal bicho, de los Fabulosos Cadillacs, en donde se abordaba la discriminación y la censura, ocupaba los primeros puestos en ventas, mientras que la primera década del siglo XXI nos ha mostrado, en el podium de la radio y la televisión, la exaltación del vitalismo erótico más efímero, como el tema monopólico de la música más difundida de Latinoamérica.

A su vez, los personajes de todas las imágenes publicitarias son jóvenes que sostienen la obsesión colectiva que tenemos por la velocidad, la obsolescencia, la novedad y la belleza; legitimando un orden social desde su sugerente invitación al consumo, propuesta meticulosamente desde los insigths de los grandes públicos. Como señala Victoria de Grazia (2006), la publicidad más que vender objetos construye un lenguaje con sentido sobre los objetos, los carga semánticamente, les da vida. En esa relación entre producción, construcción sociocultural de lo valioso y consumo - la cual no es propiedad de la publicidad, pero en la que ella sí tiene un lugar privilegiado- se esconde uno de los resortes que aseguran el manto cálido y pesado que sostiene las crisis.

La dictadura simbólica de lo juvenil es la dictadura de lo cambiante, de lo nuevo. El asunto es que cambiar constantemente implica un sujeto inconforme, no crítico, sino en crisis, no crítico porque la criticidad, la verdadera, no es obsolescente, sino que supera conservando, por ponerlo en términos hegelianos. Ese sujeto fáustico, retomando el análisis que Marshall Berman (1991) hace sobre la obra de Goethe, que lo sueña todo, lo devora todo, lo desecha todo, parece estar en el corazón de los discursos desde los que se estructura el sentido de lo juvenil.

El sujeto, desposeído de pertenencia, se consume en la volatilidad de la satisfacción y los sentidos. No hay meta posible, cada sensación remite a otra bajo la certeza de que, sin falta, descubrirás que puedes ir más lejos [...] la época del consumo es la sensación de palpar eso en que ahora sí te sentirás único, los demás te admirarán o hallarás tu verdad (Perea, 2008, p. 27).

Los jóvenes están en el ojo del huracán, estimulados a la autenticidad y a la visibilidad. Ellos, sin saberlo, ofician como guías culturales, acostumbrándonos a una reinvención abrumadora y constante; pero a la vez, son quienes siguen proponiendo lecturas interesantes y fecundas sobre la situación crítica que hemos buscado delinear. Esto último no entra en contrasentido con lo que hemos planteado hasta este punto, sino que por el contrario lo complementa.

Hasta acá hemos hablado de las contradicciones críticas que enmarcan a los jóvenes; sin embargo, no podríamos soslayar los movimientos de resistencia, la mayoría desde la agencia cultural, que son abanderados por los mismos jóvenes. Así como existe el buen heredero o el gran hedonista como estereotipos publicitarios, musicales y como caricaturas de los sujetos juveniles, también existen los jóvenes-proyecto que se organizan y proponen desde sus centros de gravedad, otras alternativas (más o menos resistentes) frente a la naturalizada cotidianidad que los envuelve. Analicemos más detenidamente esta ambivalencia. 
Hemos identificado algunas actitudes de los estudiosos frente a los jóvenes contemporáneos. Algunos parecen terminar por estigmatizar la juventud desde prejuicios adultos y retrógrados. Otros parecen muy entusiastas y sobredimensionan el agenciamiento de los jóvenes, sin someter a la mirada crítica y necesaria que cuestiona los aparatajes culturales y materiales que determinan la condición social de la juventud, en relación a unos poderes establecidos que también operan en ellos; lo que termina convirtiendo - así sea en el papel- el deseo transformador en prácticas pro hegemónicas. Otros, por su lado, reconocen la posibilidad de agencia de los jóvenes, pero ven críticamente la manera en la que se elabora la condición social de la juventud.

Martín Barbero, Marc Auge y Michel Mafessoli nos ayudan a comprender las condiciones estructurales y las subjetividades juveniles más allá de la construcción rebelde, propia de los medios de comunicación y del sentido común. Traigamos a colación lo planteado por Martín Barbero cuando reclama a las sociedades latinoamericanas sobre las condiciones estructurales que enmarcan a sus juventudes:

¿Con qué queremos que sueñe una juventud alimentada cotidianamente - no sólo y no tanto en la televisión sino en la casa, la calle, en el trabajo- con el afán de lucro fácil, con el dinero y el confort como valores supremos, con la confusión del inteligente con el listo, es decir, con el que sabe engañar y trepar rápido, con la corrupción como estrategia de ascenso tanto en la clase política como empresarial? ¿Qué entusiasmo por los proyectos colectivos le están transmitiendo las derechas y las izquierdas? ¿Qué imágenes de respeto a las normas le enseñan hoy unos ciudadanos mayoritariamente tramposos, ventajistas, aprovechados? ¿Qué experiencias de solidaridad o generosidad les ofrece hoy a los jóvenes una sociedad desconfiada, recelosa, profundamente injusta y sin embargo estancada y conformista? (2009, p.23).

En la voz de los autores parece repetirse la misma melodía: ausencia de proyecto colectivo, desasimiento de los jóvenes frente a lo político, vacío entre multiplicidad de símbolos, debilitamiento del vínculo social. Casi al unísono, Auge denuncia la inoperancia de las instituciones para proponer las finalidades:

El problema actual es que las instituciones y, a través de los medios de comunicación las instituciones políticas no hablan ya de las finalidades, no hacen nada sino gestionar el presente. Frente a la evidencia del presente utilizan palabras evidentes en apariencia, palabras antiguas o nuevas o renovadas: democracia, derechos humanos, lo humanitario, mercado, gobernancia, compasión, pero también injerencia, terrorismo, seguridad. Pero no tienen nada que decir sobre el futuro, no tienen nada que decir a los jóvenes (2008, p. 26).

Aparece de nuevo, en nuestra reflexión, la orientación al tiempo. La crisis parece haber desdibujado la relación con el pasado y las proyecciones de un futuro. Al respecto complementa Maffesoli:

La característica esencial de ese multitudinarismo es que no busca el sentido lejano (de manera aristotélica), sino que el sentido se agota en el acto. En el fondo no es otra cosa que el presente o el presentismo, recordando que hay momentos y culturas en las que el presente crea lazos, produce sentidos, aún si esos sentidos no se inscriben en la finalidad (2008, p.35).

El presentismo, la adecuación, el integrarse hoy, parece ser la orientación de los jóvenes, o al menos de una buena parte de ellos, quienes descreídos de las finalidades, definen su agenciamiento en el aquí y el ahora. En nuestro primer acercamiento a las organizaciones de la localidad de Kennedy pudimos notar que más que proyectos de transformación estructural de la sociedad, la acción colectiva se enfoca a la reivindicación de derechos, expresada en la posesión de bienes y en el acceso a los servicios. La participación comunitaria, como escenario de lucha, nos muestra las organizaciones juveniles en un proceso de autogestión localista y de gestión de recursos frente a los gobiernos locales. Allí, los jóvenes sujetos de la investigación, aquellos vinculados a procesos colectivos, construyen sentidos, generan lazos, vínculos sociales, pero también, consciente o inconscientemente, legitiman el accionar del Estado. 


\section{La acción colectiva como alternativa a la crisis}

Parece haber un elemento común en los autores que hemos citado: la crisis está en la desarticulación de los sujetos con el orden de lo colectivo. La atomización y la hiper-individualización son síntomas de la fragmentación de los sujetos y del tejido entre sujetos. No obstante, colegir que todos los sujetos están desarticulados, soslaya todas las acciones colectivas que, aún en las condiciones contemporáneas que hemos delineado, producen sentido y toman posición frente a las estructuras.

Es muy maniqueo caer en una visión totalizante tanto en términos entusiastas como pesimistas.

Los vínculos sociales aparecen amenazados por las particularidades de la sociedad de consumo. En nuestro país, con todas las condiciones estructurales de un capitalismo periférico, de una sociedad multicultural, de regiones asimétricas (a todo nivel), "la desestructuración de la convivencia es, pues, el gran desafío cultural y político". (Perea 2001, p. 39). Reconstruir el vínculo social, sin ir en desmedro de la autonomía subjetiva, es el ideal del entramado social. La autonomía dependiente, entendida por la condición de un sujeto que busca la autenticidad sin renunciar a la pertenencia (la idea es de Perea), aparece como una alternativa a la crisis. Ser con el otro, reorganizar los lazos que sirven de cemento intersubjetivo, podría ser, al menos en términos conceptuales, la razón de ser de la acción colectiva y de las organizaciones. Para el caso de los jóvenes, objetivo número uno de la individualización y la ficción de la autenticidad, las organizaciones sociales representan la posibilidad de hacer contravía y pensar el vínculo como la posibilidad de subvertir la norma. Esa es la tesis, el polo positivo de la dialéctica. Sin embargo, también es necesario abordar la antítesis, una manera crítica de ver la acción colectiva juvenil, para no caer en naturalizarla desde el más ingenuo romanticismo.
Por ahora plantearemos que la acción colectiva puede ser un escenario para subvertir el orden en cuanto rompe con el aislamiento propuesto por la sociedad de consumo. Pongamos lo dicho en diálogo con Pérez Tornero, quien al sospechar de la heroicidad de los jóvenes nos da el argumento para pensar la emancipación:

El joven será el héroe retórico y falso de nuestro universo cultural mientras se someta voluntariamente al aislamiento autocomplaciente que le propone el sistema. Este aislamiento hace de él un ávido consumidor y un inapetente sujeto que ignora, por sistema, al otro (2009, p. 276).

Otra paradoja: el aislamiento complace pero mutila. La predisposición al aislamiento no es, desde lo ideológico, más que una forma de legitimar un sistema opresivo. Aparece, por lo tanto, el vínculo como posibilidad, como el escenario de lo instituyente, de lo estructurante. La pregunta entonces pasa por un meridiano más complejo: si el vínculo es la posibilidad de la contravía, de la alternativa, de hacer consciente una crisis que individualiza y divide, ¿que es eso que nos permite actuar juntos?, ¿cómo hacerlo?, ¿para qué hacerlo?, ¿quién lo ha hecho?, ¿cómo lo ha hecho?, ¿qué ha obtenido?

Carlos Mario Perea se pregunta ¿qué nos une?; nosotros focalizamos el cuestionamiento a un sector particular de la población: ¿qué une a los jóvenes? Nuestra apuesta le apunta a tres elementos que, al menos en el contexto bogotano, generan sinergia y articulan buena parte de la acción colectiva juvenil, en particular, en el contexto en el que trabajamos, estos elementos son: (1) La producción y consumo cultural. (2) La reivindicación política y social y (3) las reivindicaciones identitarias, en particular, las de género y etnia.

La producción estética ${ }^{3}$, el agenciamiento político y la reivindicación identitaria parecen ser puntos nodales, elementos aglutinadores

3 Buena parte de las organizaciones juveniles - a nivel Bogotá, según el Directorio de organizaciones sociales poblacionales y territoriales de Bogotá. Bogotá 2009—, están articuladas en torno de alguna práctica artística. Organizaciones de teatro, de música, de producción audiovisual, entre otras. Esta motivación parece ser la más efectiva dentro de los jóvenes. 
entre los jóvenes. Los tres articulan buena parte de las prácticas y discursos juveniles, en un contexto como Bogotá. Además, entre estos tres tópicos articuladores se tejen puentes que hacen más complejas las acciones de las que hablamos.

Estos tres elementos aglutinadores pueden articularse entre sí y tomar forma en el accionar de sujetos colectivos (organizaciones juveniles) que operan en el marco de la ciudad. Aunque sirvan como escenario o ruta para pensar la formación de una conciencia política que vaya más allá de la reivindicación localista, también están atravesados por unas contradicciones no tan aparentes y por la semilla misma de la crisis.

Revisando las historias de vida que desarrollamos en la investigación que da origen a este ensayo, 10 historias de vida de los líderes juveniles de la localidad de Kennedy, vemos cómo la agencia cultural adquiere una relevancia importante en los escenarios de participación social y política juvenil. Muchas de las acciones políticas son en realidad movidas culturales, lo que necesariamente no las invalida, pero sí las pone en el terreno del disfrute más que en el de la lucha consciente por la construcción de una ciudadanía activa. Desde la dimensión de las culturas juveniles transnacionales y desde todos los distintos discursos y prácticas que allí convergen, la producción cultural y simbólica es un elemento aglutinador entre los jóvenes; pero también, desde la resistencia popular y desde la misma ausencia de posibilidades para el consumo, los jóvenes se articulan en torno a la producción de música, de las artes graficas, literarias, audiovisuales, entre otras. Estas posibilidades de convergencia y grupalidad que plantea el arte son una salida a la crisis, en cuanto fortalecen la soga que rodea el grupo.

Sin embargo, al estar referidas simplemente a la producción, circulación y posicionamiento de bienes culturales, terminan haciendo que la acción colectiva se focalice en reivindicaciones de sujetos concretos y en la organización de espacios de distensión, y no en el desarrollo de procesos que institucionalicen prácticas que puedan transformar las asimetrías que envuelven a los jóvenes.

No obstante, la reivindicación política y social sigue teniendo un lugar en el mundo de la vida, aunque este lugar puede verse amenazado por el clientelismo y la instrumentalización de la participación política juvenil por parte del Estado.

Así mismo, las reivindicaciones de género y etnia, por poner un ejemplo bastante común abordado en múltiples investigaciones, proponen a los sujetos formas de anclarse a procesos colectivos, lo que deviene en hacer una contravía a la situación crítica que hemos planteado. Quizás, si estas reivindicaciones estuvieran orientadas más allá del reconocimiento fragmentado, asociado exclusivamente a lo étnico o a las condiciones de género, como efectivamente sucede en algunos casos, los procesos de acción colectiva juvenil podrían fortalecerse más. La intención de esta reflexión apunta a ese norte. Más que desvirtuar las invaluables opciones de acción colectiva juvenil, quisimos pensar que, si bien son una contravía a la crisis, deben someterse a la autocrítica y descentrarse de la agencia cultural como única herramienta de lucha.

\section{Coda}

¿Vivimos una crisis? Sí. A pesar de la desmedida oferta simbólica de nuestras sociedades, la experiencia de los sujetos está atravesada por una sensación de vacío. Las condiciones materiales parecen reproducir las asimetrías del capitalismo. Dentro de las múltiples posibilidades de enfrentar la crisis, la acción colectiva y la organización social y comunitaria aparecen como alternativas. En el caso particular de los jóvenes, la acción colectiva se da de manera espontánea y deviene en proyectos socioculturales y económicos que terminan por intervenir en la realidad. 
No obstante, debe verse de manera crítica el hecho de que buena parte de las acciones colectivas se sustenten en la proposición de espacios de entretenimiento, en cuanto éstos podrían dejar de lado las reivindicaciones desde el plano de lo material, que es determinante para disminuir las determinaciones del capitalismo. Desde este punto recogemos lo planteado por Heath y Potter, en el texto Revelarse vende; una propuesta critica frente a la contracultura (criticidad frente a lo aparentemente crítico), en donde se resaltan cómo los movimientos y organizaciones sociales, a veces con procesos menos divertidos, terminan por generar una transformación social más certera. Despidámonos con la siguiente cita:

\section{Referencias bibliográficas}

Auge, M. (2012). La comunidad ilusoria. Barcelona: Gedisa.

Barbero, J. M. (2009). Jovenes: des-orden cultural y palimpsestos de identidad. En Diuc, viviendo a toda. Bogotá: Siglo del hombre.

Bauman, Z. (2003). Comunidad. En busca de seguridad en un mundo hostil. Madrid: Siglo XXI.

. (2006). Libertad. Buenos Aires: Losada.

De Grazia, V. (2006). El imperio Irresistible.España: Belacqva.

Heath, J., \& Potter, A. (2004). Rebelarse vende, el negocio de la contracultura. Madrid: Taurus.

Lipovetsky, G. (2003). La era del vació. España: Anagrama.

Mafessolli, M. (2008). El arcaísmo posmoderno. En C. E. Pinzón Castaño, G. Garay Ariza \& R. Suárez Prieto (Eds.), Para cartografiar la
En cuanto a la justicia social, los grandes logros obtenidos en Norteamérica durante el último medio siglo proceden de una reforma sistemática llevada a cabo dentro del sistema. Tanto los movimientos pro derechos civiles como el feminismo han beneficiado enormemente a determinados sectores desfavorecidos, al tiempo que la protección social proporcionada por el estado del bienestar mejoraba las condiciones de vida de todos los ciudadanos. Pero estas mejoras no se han conseguido "desenchufando" a las personas de la red de ilusiones que gobiernan sus vidas. Se deben a un laborioso proceso de política democrática basada en el debate, la investigación, la coalición y la reforma legislativa. Este nos parece el camino que hay que seguir. Puede que sea menos ameno, pero potencialmente es mucho más útil (Heath \& Potter, 2004, p. 20).

diversidad de los jóvenes. Bogotá: Universidad Nacional de Colombia.

Marshall, B. (1991). Todo lo sólido se desvanece en el aire. La experiencia de la modernidad Colombia: Siglo XXI.

Perea, C. M. (2008). Que nos une. Bogotá: La Carreta.

Pérez Tornero, J. M. (2008). El ansia de identidad juvenil y la educación. Del narcisismo mediático contemporaneo y las estrategias educativas. En H. J. Cubides C, M. C. Laverde Toscano \& C. E. Valderrama H. (Eds.), Viviendo a toda. Bogotá: Siglo del hombre.

Sorokin, P. A. (1960). Las filosofías sociales de nuestra época de crisis: el hombre frente a la crisis. Madrid: Aguilar.

Taylor, C. (1994). La ética de la autenticidad. Barcelona: Paidos. 